investigation is warranted to confirm these preliminary findings.

\section{References}

1. Tacconi F, Pompeo E, Mineo TC. Duration of air leak is reduced after awake nonresectional lung volume reduction surgery. Eur J Cardiothorac Surg. 2009;35: 822-8; discussion 828
2. Cerfolio RJ, Bryant AS, Maniscalco LM. Management of subcutaneous emphysema after pulmonary resection. Ann Thorac Surg. 2008;85:1759-63; discussion 1764-5.

3. Matsushita T, Huynh AT, Singh T, Thomson D. Management of life-threatening subcutaneous emphysema using subcutaneous Penrose drains and colostomy bags. Heart Lung Circ. 2007;16:469-71.

4. Beck Pl, Heitman SJ, Mody CH. Simple construction of a subcutaneous catheter for treatment of severe subcutaneous emphysema. Chest. 2002;121:647-9.

\title{
Innovative techniques for thoracoscopic lobectomy in postpneumonectomy patients
}

\author{
Ryoichi Nakanishi, MD, PhD, ${ }^{\mathrm{a}}$ Shinji Shinohara, MD, ${ }^{\mathrm{a}}$ Kenji Muranaka, MD, ${ }^{\mathrm{b}}$ and Koichi Shinohara, MD, \\ Kitakyushu, Japan
}

\section{PTCS VIDEO}

Video clip is available online.

It is extremely difficult to perform a thoracoscopic lobectomy for non-small cell lung cancer in postpneumonectomy patients because lung collapse as classically practiced is not an option. Collapse of the lobe to be resected and effective retraction of the other inflated lobes allow surgeons to perform thoracoscopic procedures in such patients. This report presents several innovations regarding thoracoscopic middle lobectomy in patients with a favorable pulmonary function who previously underwent left pneumonectomy.

\section{SURGICAL PROCEDURES}

The patient was placed in a supine position under general anesthesia with a spiral endotracheal tube. A Coopdech endobronchial blocker tube (Daiken Medical, Osaka, Japan) was introduced into the lobar bronchus to be resected under bronchoscopy, performed via an endotracheal tube. The lobe to be resected collapsed after the balloon was inflated.

From the Department of Thoracic Surgery, ${ }^{\mathrm{a}}$ and the Department of Anesthesiology, ${ }^{\mathrm{b}}$ Shin-Kokura Hospital, Federation of National Public Service, Personnel Mutual Aid Associations, Kokurakita-ku, Kitakyushu, Japan.

Disclosures: Authors have nothing to disclose with regard to commercial support.

Received for publication Feb 21, 2013; revisions received April 1, 2013; accepted for publication April 9, 2013; available ahead of print June 13, 2013.

Address for reprints: Ryoichi Nakanishi, MD, PhD, Department of Thoracic Surgery, Shin-Kokura Hospital, Federation of National Public Service, Personnel Mutual Aid Associations, Kanada 1-3-1, Kokurakita-ku, Kitakyushu, 803-8505, Japan (E-mail: ryoichi@med.uoeh-u.ac.jp).

J Thorac Cardiovasc Surg 2013;146:724-5

$0022-5223 / \$ 36.00$

Copyright (c) 2013 by The American Association for Thoracic Surgery

http://dx.doi.org/10.1016/j.jtcvs.2013.04.013
The surgery was begun after confirmation of absence of hypoxemia. ${ }^{1}$

While paying close attention to avoid any injury to the inflated lung, an access window measuring $30 \mathrm{~mm}$ in length was first placed in the fourth intercostal space on the anterior axillary line because of easy access to the hilar structures and effective retraction of the lower lobe. An additional 12-mm-diameter port was placed in the fifth intercostal space on the midclavicular line for a $10-\mathrm{mm}$ thoracoscope. The inflated lower lobe then was retracted posteriorly using 2 devices (Endoractor, Kawamoto Co,

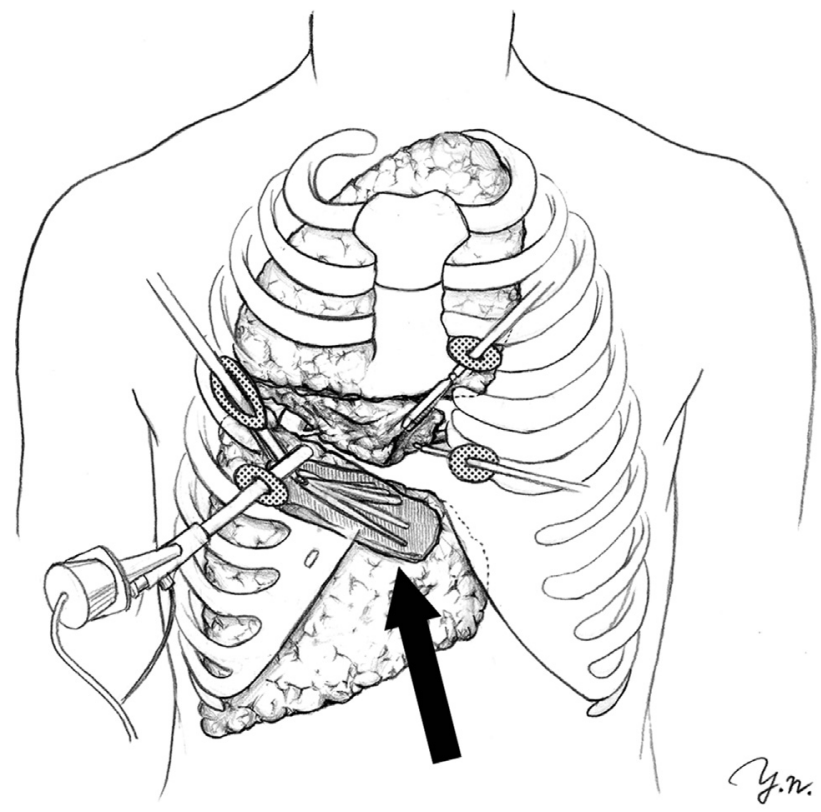

FIGURE 1. Surgical maneuvers are shown with the patient positioned in the supine position. The arrow indicates the right lower lobe, which is retracted by the Endo Retract II on contact with the swollen Endoractor sponge. 


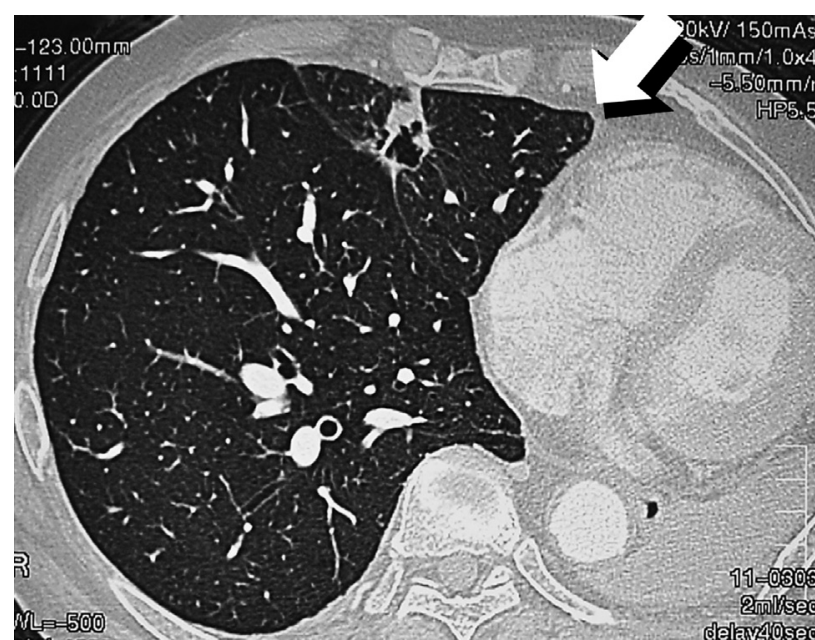

FIGURE 2. Computed tomographic scan of the chest shows an abnormal mass in the middle lobe of the lung in a 75-year-old man, who underwent left pneumonectomy 6 years previously. Tumor histology and stage was squamous cell carcinoma and T1aN0M0 stage IA, respectively. The arrow indicates the port sites on the contralateral sternal border.

Osaka, Japan; and Endo Retract II, Tyco Healthcare, Norwalk, Conn) through the access window to extend the working space made by the collapsed middle lobe (Figure 1). The Endoractor sponge was placed on the interlobar surface of the right lower lobe and became swollen after absorbing the sprayed saline solution. The right lower lobe was covered with the swollen sponge and then retracted using the Endo Retract II on contact with the sponge. Two additional $12-\mathrm{mm}$ port sites then were created at the third and fifth intercostal spaces on the contralateral sternal border where there was easy access to the anterior hilar space despite overexpansion of the affected lung (Figure 2). The pulmonary vein was identified easily and was divided with an endoscopic $2.5-\mathrm{mm}$ staple after a hilar lymph node dissection. Second, the interlobar pulmonary artery was dissected carefully through the access window, and was divided with an energy device after ligation of the artery. After dissection of the interlobar and lobar lymph nodes, the bronchus then was divided with an endoscopic $3.5-\mathrm{mm}$ staple during minimal apnea after extraction of the endobronchial blocker tube. While viewing a video monitor, the surgery was completed with no rib spreading and without any problems (Video 1).

\section{DISCUSSION}

To create a sufficient working space for thoracoscopic lobectomy in postpneumonectomy patients, the technique of lobe-selective bronchial blockade is superior to extracorporeal lung assistance because it is easier to perform and does not require the use of anticoagulant agents. ${ }^{2,3}$
High-frequency jet ventilation creates a limited working space, which results in incomplete atelectasis of the lobe to be resected. ${ }^{4,5}$ Incomplete atelectasis requires the use of another retractor system. This technique may be impacted by incomplete fissures and collateral ventilation, although no problems were observed in this study.

An overexpansion of the affected lung often is seen in postpneumonectomy patients. Both the surgical position and port-site strategy require a case-by-case approach because of rotated mediastinal and hilar structures. In comparison with previous treatment, a supine position and an unusual port-site strategy including placement on the contralateral sternal border thus may allow for easy access to the hilar space despite the overexpansion of the affected lung. The other port sites must be placed suitably to allow for the retraction of the inflated lung because maximizing the intrathoracic working space is the cornerstone of the success of this surgery. ${ }^{1}$

The use of the Endoractor allows for the retraction of a wide range of the inflated lung as a result of the ability to expand the device up to $72 \mathrm{~mm}$ long by $260 \mathrm{~mm}$ wide and can reduce the risk of damage to the inflated lung because the device is composed of a sponge. Furthermore, the sponge easily can pass through a $10-\mathrm{mm}$ diameter port as a result of its $8-\mathrm{mm}$ thickness. The development of new devices as well as increases in skill may be associated with shorter surgical times and reduced wound length in comparison with previous surgical methods.

In conclusion, innovations using selective bronchial blockade of the lobe to be resected, an unusual port-site placement including left parasternal incision, and a creative retractor system with new devices for the inflated lung allow the surgeon to easily perform a thoracoscopic lobectomy in a postpneumonectomy patient.

\section{References}

1. Nakanishi R, Hirai A, Muranaka K, Shinohara K. Successful video-assisted thoracic surgery lobectomy in a single-lung patient. Surg Laparosc Endosc Percutan Tech. 2007;17:562-4.

2. Morikawa T, Sugiura H, Kaji M, Sasamura Y, Okushiba S, Kondo S, et al. Availability of lobe-selective bronchial blockade for video-assisted thoracic surgery: an initial experience with three cases. Surg Endosc. 2002;16:327-30.

3. Iacovazzi M, Oreste N, Sardelli P, Barrettara B, Grasso S. Extracorporeal carbon dioxide removal for additional pulmonary resection after pneumonectomy. Minerva Anestesiol. 2012;78:381-4.

4. Ishiyama T, Iwashita H, Shibuya K, Terada Y, Masamune T, Nakadate Y, et al. High-frequency jet ventilation during video-assisted thoracoscopic surgery in a patient with previous contralateral pneumonectomy. J Clin Anesth. 2013;25: 55-7.

5. Nakanishi R, Yamashita T, Muranaka K, Shinohara K. Thoracoscopic carinal resection and reconstruction in a patient with mucoepidermoid carcinoma. $J$ Thorac Cardiovasc Surg. 2013;145:1134-5. 